\title{
A terceira idade no contexto das políticas públicas para a Educaçáo de Jovens e Adultos (1988-2011)
}

\author{
Danilo Rabelo* \\ Simone C. Rodrigues da Silva**
}

\section{Resumo}

Este artigo aborda o desenvolvimento de políticas públicas para a EJA, a partir da LDBEN e do Estatuto do Idoso, visando destacar os avanços e os entraves desta modalidade de ensino, especialmente na alfabetização do sujeito idoso. Apesar das mudanças com a implantação do Estatuto e da Política Nacional do Idoso, da Constituiçáo e da LDBEN, constata-se, pelos dados do IBGE de 2010, que o Brasil ainda tem um longo caminho a percorrer para oferecer aos jovens, adultos e idosos um ensino de qualidade. Também são enfocados os mecanismos de exclusão dos sujeitos idosos no contexto das políticas públicas para a Educação de Jovens e Adultos (EJA).

Palavras-chave: políticas públicas e educacionais, Educação de Jovens e Adultos (EJA), ensino e aprendizagem na terceira idade, diversidade cultural.

\section{The elderly in the context of Public Policies for the Education of Young People and Adults (1988-2011)}

\section{Abstract}

This paper studies the drafting of public polices for the Education of Young People and Adults based on LDBEN (Laws and educational guidelines as a basis for national education) and the Statute of the Elderly and highlights the improvements and obstacles faced by this teaching modality, in particular, the literacy of elderly. Despite the changes brought about by the Statute and National Policy for the Elderly, the Constitution and the LDBEN, it can be seen from the 2010 IBGE data that Brazil still has a long way to go if it is to offer quality teaching for the young, adults and the elderly. The study also focused on the mechanics of exclusion of the elderly in the context of public policies for the Education of young people and adults.

Keywords: public and educational policies, Education of Young People and Adults (EJA), teaching and learning for the elderly, cultural diversity.

* Doutor em História pela UnB (2006), sociólogo; professor do Cepae e do Programa de Pós-Graduação em História da Universidade Federal de Goiás. E-mail: rabelodanilo62@yahoo. com.br

** Pedagoga, especialista em Metodologia do Ensino Fundamental pela Universidade Federal de Goiás (2012). E-mail: simone.conceição@gmail.com 


\section{Introdução}

No Brasil, as estatísticas apontam que o número de idosos no mundo cresce largamente. "Entre 1960 e 2020 estima-se em 760\% o crescimento do número de idosos e em 166\% o de jovens" (CHAIMOWICZ, 1997, p. 184). Em 2007, a Pesquisa Nacional por Amostra de Domicílios (PNAD) revelou a existência, no Brasil, de quase 20 milhóes de idosos, correspondendo assim a 10,5\% da população (PAULA, 2009, p. 31). Por sua vez, o Censo de 2010 (IBGE) registrou o total de 13,9 milhóes de analfabetos com 15 anos ou mais, o equivalente a 9,3\% da população do país.

Assim, o presente artigo tem o objetivo de analisar os avanços, os entraves e as contribuiçóes das políticas públicas para uma ação inclusiva que valorize a diversidade e a terceira idade.

A Educação de Jovens e Adultos, na escolarização, muitas vezes é visualizada como uma ação informal, e nesse contexto é possível delinear, de acordo com Gadotti e Romão (2002), que às vezes é, sim, concebida como uma educação não formal, ou até como uma área especializada para administrar este ensino.

$\mathrm{Na}$ verdade, a EJA não se diferencia da educação regular. Ao contrário, ambas estáo intimamente ligadas, uma vez que fazem parte do mesmo processo. Só porque sua clientela é composta de pessoas vividas, experientes, não significa que elas náo estejam em busca do conhecimento. Desse modo, o aprendizado é algo construído dentro de um sistema formal, ou seja, na escolarização para alfabetizar e letrar os discentes, isto é, formar o indivíduo de forma integral.

A formação integral do ser humano ocorre nos aspectos cognitivo, intelectual e cultural, assim é um educar que almeja a inserção deste ser no mundo, como forma de prepará-lo para enfrentar os desafios sociais, políticos, econômicos e educacionais impostos pela sociedade, como sustenta Haidt (2006, p. 11): "a educação é uma manifestação de cultura e depende do contexto histórico e social em que está inserida. [...] é a transmissão, pelas geraçóes adultas, de valores, normas, usos, costumes, conhecimentos às gerações mais jovens".

Ao se falar em educaçáo, automaticamente se faz referência ao termo "cultura". Os alunos, quando chegam à escola, já carregam consigo uma bagagem preenchida por valores e sabedorias construídos a partir dos ensinamentos passados pelos mais velhos, de modo que no contexto escolar 
da Educaçáo de Jovens, Adultos e Idosos torna-se um ensinar específico. Esses alunos, apesar de não terem o domínio da leitura e da escrita, já trazem, no auge da vida, conhecimentos e valores importantes e necessários à educação, construídos ao longo do tempo.

Do ponto de vista pedagógico, a educação de jovens, adultos e idosos ocorre em uma relação mútua entre aprender x ensinar, isto é, uma mediação dialética na construção do conhecimento, uma vez que o professor, ao ensinar uma determinada disciplina, como, por exemplo, o Meio Ambiente, poderá se surpreender com o conhecimento de sua turma; da mesma forma que está ensinando, o docente está aprendendo com o educando.

$\mathrm{O}$ processo de ensino-aprendizagem na educação, de acordo com Lopes et al. (2011), é um processo dinâmico, que não pode ser considerado e visualizado pelo professor, na sala de aula, como algo acabado, mas sim contínuo. Um processo dinâmico e contínuo, que visa à formação de cidadãos críticos e autônomos, como forma de respeitar e valorizar os princípios elencados na LDBEN, que é a preparação do ser humano para a vida.

Para Freire (2007), o domínio para ler e escrever conquistado na alfabetização de jovens, adultos e idosos deve ser visto como uma oportunidade que os indivíduos têm para perceberem o verdadeiro significado da palavra e, assim, exercerem o direito de usufruir dessa ferramenta para se expressar, criar e fazer escolhas na sociedade.

Todavia, ao se constatar os dados alarmantes colhidos pelo IBGE sobre os analfabetos funcionais (indivíduos que não dominam a prática da leitura e nem conseguem entender e assimilar o que a mensagem escrita quer transmitir), poder-se-ia perguntar: qual o papel das políticas públicas nessa práxis?

\section{A Educação de Jovens, Adultos e Idosos no Brasil a partir da LDBEN de 1996 e do PNE de 2001}

A Constituição de 1988, em nível discursivo, veio atender aos anseios da sociedade brasileira por um ensino igualitário e acessível a todos, inclusive aos jovens e adultos:

Art. 205 - A educação, direito de todos e dever do Estado e da família, será promovida e incentivada com a colaboração da sociedade, visando 
ao pleno desenvolvimento da pessoa, seu preparo para o exercício da cidadania e sua qualificação para o trabalho [...].

Art. 208 - O dever do Estado com a educação será efetivado mediante a garantia de: I - educação básica obrigatória e gratuita dos 4 (quatro) aos 17 (dezessete) anos de idade, assegurada inclusive sua oferta gratuita para todos os que a ela não tiveram acesso na idade própria; [...] VI oferta de ensino noturno regular, adequado às condiçóes do educando. Art. 214 - A lei estabelecerá o plano nacional de educação, de duração decenal, com o objetivo de articular o sistema nacional de educação em regime de colaboração e definir diretrizes, objetivos, metas e estratégias de implementação, para assegurar a manutenção e desenvolvimento do ensino em seus diversos níveis, etapas e modalidades por meio de açóes integradas dos poderes públicos das diferentes esferas federativas, que conduzam a: I - erradicação do analfabetismo; II - universalização do atendimento escolar; III - melhoria da qualidade do ensino; IV - formação para o trabalho; $\mathrm{V}$ - promoção humanística, científica e tecnológica do País. VI - estabelecimento de meta de aplicação de recursos públicos em educação como proporção do produto interno bruto. (BRASIL, 1988)

A educação no Brasil passava a ser um direito de todos e o Estado, por sua vez, não se eximia de sua responsabilidade para com o povo brasileiro. Os adultos e idosos teriam acesso a uma sala de aula com profissionais que tinham o objetivo de prepará-los para o mercado de trabalho e, acima de tudo, para a cidadania plena. No mesmo espírito do artigo 208, da Constituição de 1988, o artigo 37 da LDBEN n. 9.394, de 20 de dezembro de 1996, prevê para a EJA:

Art. 37 - A educação de jovens e adultos será destinada àqueles que não tiveram acesso ou continuidade de estudos no ensino fundamental e médio na idade própria.

$\$ 1^{\circ}$ Os sistemas de ensino asseguraráo gratuitamente aos jovens e adultos, que náo puderam efetuar os estudos na idade regular, oportunidades educacionais apropriadas, consideradas as características do alunado, seus interesses, condiçóes de vida e de trabalho, mediante cursos e exames.

$\$ 2^{\circ}$ o Poder Público viabilizará e estimulará o acesso e a permanência do trabalhador na escola, mediante açóes integradas e complementares entre si. (BRASIL, 1996)

Entre os anos de 1996 e 2001 houve um intenso debate sobre a elaboração do Plano Nacional de Educação (PNE), e duas propostas foram apresentadas ao Congresso em 1998. Uma proposta do governo e uma 
proposta da sociedade civil, consubstanciada no II Congresso Nacional de Educação (CONED), ocorrido em novembro de 1997, na cidade de Belo Horizonte-MG.

Segundo Di Pierro (2010, p. 942-943), as duas propostas do PNE não diferiam quanto às concepçóes de formação de pessoas jovens e adultas, não aderiam a perspectivas inovadoras, nem se alinhavam aos paradigmas da educação popular ou da educação continuada ao longo da vida. Ambos os documentos limitavam-se a desenhar estratégias de elevação das taxas de alfabetização e níveis de escolaridade da população, ocupando-se da reposição de estudos náo realizados na infância ou adolescência, o que os situa nos marcos da concepção compensatória da EJA. A distinção mais evidente entre os dois projetos residia nos critérios e mecanismos de financiamento da EJA.

A Lei n. 10.172, de 9 de janeiro de 2001, instituiu o Plano Nacional de Educação (PNE) para o decênio 2001-2011. No Capítulo V do PNE se estabeleceram as diretrizes para a EJA, tendo em vista principalmente a erradicação do analfabetismo. O diagnóstico do PNE demonstrou a desigual distribuição das taxas de analfabetismo absoluto e funcional entres as zonas rural e urbana e os grupos de idade, sexo e etnia, sendo necessário propor ações de escolarização que atingissem não só os jovens, como também os adultos e idosos (ibidem, 2010, p. 944). Quanto às diretrizes, o PNE

alterou a concepçáo tradicional de educaçáo de jovens e adultos, não mais restrita a um período particular da vida ou a uma finalidade circunscrita. Desenvolve-se o conceito de educação ao longo de toda a vida, que há de se iniciar com a alfabetizaçáo. Mas não basta ensinar a ler e a escrever. Para inserir a população no exercício pleno da cidadania, melhorar sua qualidade de vida e de fruição do tempo livre, e ampliar suas oportunidades no mercado de trabalho, a educação de jovens e adultos deve compreender, no mínimo, a oferta de uma formaçáo equivalente às oito séries iniciais do ensino fundamental. (BRASIL, 2001)

Nas 26 metas para a EJA propostas pelo PNE, podem-se destacar cinco objetivos: 1) alfabetizar, em cinco anos, dez milhôes de pessoas, de modo a erradicar o analfabetismo em uma década; 2) assegurar, em cinco anos, a oferta do primeiro ciclo do ensino fundamental à metade da população jovem e adulta que não tenha atingido esse nível de escolaridade; 3) oferecer, até o final da década, cursos do segundo ciclo do ensino fundamental para toda a populaçấo de 15 anos ou mais que concluiu as séries iniciais; 
4) dobrar, em cinco anos, e quadruplicar, em dez anos, a capacidade de atendimento nos cursos de EJA de nível médio; 5) implantar ensino básico e profissionalizante em todas as unidades prisionais e estabelecimentos que atendem a adolescentes infratores (DI PIERRO, 2010, p. 944).

No cumprimento dessas metas, o PNE previa a participação das três esferas governamentais e da sociedade civil organizada. Mas quanto ao financiamento dos recursos, "prevaleceu a proposta do executivo federal de emprego prioritário na EJA dos recursos destinados ao ensino fundamental que não integravam o FUNDEF" (ibidem, p. 945). Esse fato impediu a ampliação de recursos para essa modalidade de ensino (EJA).

Para a formação de docentes especializados em EJA, o PNE estabelecia como meta "assegurar que os sistemas estaduais de ensino, em regime de colaboração com os demais entes federativos, mantenham programas de formação de educadores de jovens e adultos" (BRASIL, 2001), perdendo, assim, a oportunidade de convocar as instituiçóes de ensino superior a considerar esse aspecto na formação inicial de professores e a se engajar na formação continuada de professores que atuam em projetos comunitários e nas redes públicas de ensino. Também, não foram fixadas estratégias ou metas para reverter desigualdades educativas entre grupos étnico-raciais e as populaçóes rurais, e nem foi instituído um monitoramento periódico dos programas de EJA (DI PIERRO, 2010, p. 945).

Não se pode negar que durante o governo do presidente Luiz Inácio Lula da Silva houve um incremento das políticas públicas educacionais para a EJA, uma vez que, a partir de então, novas propostas foram sendo consolidadas, como a criação do Programa Brasil Alfabetizado (PBA), que delineou uma nova marcha a favor da erradicação do analfabetismo no país, levando a comunidade de jovens, adultos e idosos ao caminho do saber.

Conforme o Decreto n. 6.093, de 24 de abril de 2007, o Programa Brasil Alfabetizado teve o objetivo de promover a universalização da alfabetização entre os jovens e adultos acima de 15 anos, que se encontravam fora da escolarização e se enquadravam na estatística apontada pelo IBGE (em 2000), que projetou o índice de analfabetismo no país. Dessa forma, o programa visava atender prioritariamente os locais considerados de calamidade pública pelo governo, localizados nos Estados e Municípios do território nacional, e contemplar o maior número possível de pessoas. Entretanto, para Rummert e Ventura (2007, p. 3), os programas voltados para a EJA no governo Lula 
caracterizam-se por ser mais um rearranjo do mesmo pensamento hegemônico que tem gerado, ao longo da história, um conjunto de propostas com vistas a atender, prioritariamente, às necessidades do capital nos países periféricos ou semiperiféricos. $\mathrm{O}$ caráter de amenização das tensóes sociais e dos impasses inerentes à lógica do sistema parece ser uma das funçóes cumpridas, atualmente, por diferentes programas destinados a jovens e adultos trabalhadores, como vimos, ainda hoje, sem lugar próprio no cenário educacional brasileiro.

As estatísticas projetadas pelo IBGE, em 2010, demonstram os avanços do ensino na EJA, pautados por números que levam o Brasil a mascarar o aumento no índice de alfabetização entre os brasileiros. Pois é possível perceber o número alarmante de adultos que teoricamente possuem o diploma de pessoas alfabetizadas, mas que na realidade são pessoas que apresentam analfabetismo funcional.

De acordo com o Censo Demográfico de 2010, feito pelo Instituto Brasileiro de Geografia e Estatística (IBGE), existem 65 milhôes de brasileiros com 15 anos ou mais sem nenhuma instrução ou que não concluíram o Ensino Fundamental - mas somente 4 milhões estavam na escola em 2011. O cenário piora porque o analfabetismo funcional, segundo o Inaf 2012, é o maior entre os mais velhos: $30 \%$ da população entre 35 e 49 anos e $52 \%$ da que tem mais de 50 . A isso, se soma o fato de as matrículas estarem caindo. Entre 2007 e 2011, houve um decréscimo de cerca de 760 mil em 20 redes estaduais e no Distrito Federal. (FERNANDES, 2012, p. 94)

O retrato simplesmente ilustra o descompromisso do Estado para com a população brasileira, ao investir em políticas públicas que não garantem a cidadania e autonomia pautadas na LDBEN e na Constituiçáo Federal. Princípios estes que deveriam proporcionar condiçóes para que o aluno possa se tornar alfabetizado e letrado, como sustenta a LDBEN. É tarefa do Estado disponibilizar condiçóes necessárias para o oferecimento de uma educação de qualidade, bem como viabilizar o pleno desenvolvimento do educando, favorecendo a aprendizagem dos componentes básicos inerentes à formação do homem, como o pleno domínio da leitura, da escrita e do cálculo.

Segundo Freire (2007), o analfabetismo não deve ser considerado como uma erva daninha, como alguns o interpretam. Deve, sim, ser enfrentado com seriedade e compromisso, por meio do desenvolvimento de açóes 
políticas efetivas para a sua erradicaçáo e para a melhoria da qualidade do ensino. Conforme ressalta o autor, o analfabetismo no país é fruto de uma realidade social injusta; assim, apenas a sua erradicação não tem um significado preponderante para melhorar o ensino.

Para Gadotti e Romão (2002), o termo "analfabetismo" está relacionado à expressão de pobreza, uma consequência da própria estrutura social imposta pelo país; assim, a concepçáo do analfabetismo náo se limita simplesmente a uma questâo pedagógica, é mais uma ação totalmente política.

Por outro lado, segundo Di Pierro (2010, p. 947), os resultados frustrantes no terreno da alfabetização de jovens e adultos são atribuídos a pelo menos três fatores combinados:

superestimação de participantes, devido à atribuição da responsabilidade de formação de turmas aos alfabetizadores e à escassa fiscalização; problemas de focalização do programa, que inscreveria, em grande medida, pessoas já alfabetizadas e não o público-alvo prioritário constituído por analfabetos absolutos; escassos resultados de aprendizagem, devido à duraçáo insuficiente dos cursos, à frequência intermitente e evasão dos alfabetizandos, à seleção inadequada e precária formação dos alfabetizadores, entre outros aspectos relativos à qualidade dos cursos.

\section{O papel das políticas públicas educacionais na escolarizaçáo dos jovens, adultos e idosos}

O envelhecimento populacional, ao contrário da esperança de vida ao nascer, não depende das taxas de mortalidade, mas resulta do declínio da fecundidade. No Brasil, segundo o censo de 2010 do IBGE, a diminuição das taxas de fecundidade e de natalidade pode ser observada a partir da análise da composição etária da população brasileira. $\mathrm{O}$ estreitamento significativo ocorrido na base da pirâmide aponta para a redução do contingente das crianças e adolescentes de até 19 anos de idade. Enquanto em 1999 a proporção desse grupo na população total era de 40,1\%, em 2009 essa participação diminuiu para $32,8 \%$. Outro ponto que merece ser destacado refere-se ao considerável incremento da população idosa de 70 anos ou mais de idade. Em 1999, a PNAD apontava para um total de 6,4 milhóes de pessoas nessa faixa etária (3,9\% da população total), enquanto em 2009 a população atingiu um efetivo de 9,7 milhôes de idosos, correspondendo a 5,1\% (IBGE, 2010, p. 28). 
De acordo com Motta (2005), a Organização das Naçôes Unidas (ONU) declara, diante das estatísticas projetadas pelo IBGE, que até 2025 o Brasil será o sexto país a compor o maior número de pessoas idosas. Diante dessa estimativa, o que fazer para enfrentar este quadro social na educação?

Para Oliveira (1999), a tendência no Brasil é valorizar o novo e, como consequência, desvalorizar o que é velho. E assim a nação brasileira busca no rol da educação manter o retrato de juventude. Silva (2002, p.65) enfatiza que "o individuo está inserido na família, na cultura, em um período histórico, e é perturbador perceber o descaso da sociedade [...], a representaçáo negativa da velhice [...], que convida o idoso a lutar pelo seu reconhecimento social". Apesar das leis que o protegem, o idoso ainda hoje é visto como inutilidade e, assim, o preconceito acaba influenciando a educação e a sociedade brasileira.

Segundo Silveira et al. (2009), o aumento da populaçáo de idosos no Brasil é um fato que deve ser encarado, de modo que se faz necessária a preocupação com as questóes que envolvem a terceira idade, no ambiente familiar, no trabalho, na educação, na vida social.

A sociedade contemporânea buscou investir em programas sociais e educacionais que valorizassem essa clientela, influenciando desse modo na sua aprendizagem. Para conduzir o ensino na EJA, buscou conhecer e respeitar as dificuldades e as peculiaridades apresentadas pelas pessoas idosas.

Mas a realidade é que pouco se tem feito para valorizar a terceira idade. Pouco se tem feito no sentido de criar mecanismos que contribuam na melhoria de sua qualidade de vida. É importante que o professor possa refletir sobre essas questóes, levando-as para o ambiente escolar como forma de debater e socializar entre os alunos dessa faixa etária.

Em 1994, a Lei n. 8.842 implementou a política nacional do idoso e criou o Conselho Nacional do Idoso, que têm o objetivo de assegurar às pessoas idosas os seus direitos expressos na prática da cidadania e autonomia plena, como forma de garantir e promover a sua integraçáo e participação no convívio social. $\mathrm{O}$ artigo 10 , inciso III, definiu assim as competências dos órgáos e entidades públicas na área educacional:

a) adequar currículos, metodologias e material didático aos programas educacionais destinados ao idoso; b) inserir nos currículos mínimos, nos diversos níveis do ensino formal, conteúdos voltados para o processo de envelhecimento, de forma a eliminar preconceitos e a produzir conhecimentos sobre o assunto; c) incluir a Gerontologia e a Geriatria como 
disciplinas curriculares nos cursos superiores; d) desenvolver programas educativos, especialmente nos meios de comunicação, a fim de informar a população sobre o processo de envelhecimento; e) desenvolver programas que adotem modalidades de ensino à distância, adequados às condiçóes do idoso; f) apoiar a criação de universidade aberta para a terceira idade, como meio de universalizar o acesso às diferentes formas do saber. (BRASIL, 1994)

Todavia, embora a Política Nacional do Idoso já existisse, não há nada em específico para a pessoa idosa na LDBEN n. 9.394/96 ou nas Diretrizes Curriculares para a Educação de Jovens e Adultos (2000). Essas leis e políticas públicas, além de não levarem em consideração a pessoa idosa, parecem agir isoladamente.

O envelhecimento gradativo da população mundial, a falta de investimento em programas sociais e educacionais e a violência sensibilizaram a Organização das Naçóes Unidas (ONU) para a promoção e o amparo à longevidade, de modo que, em 1999, no mundo inteiro celebrou-se o Ano Internacional do Idoso. Três anos depois, em Madri, a ONU divulgou o Plano de Ação Internacional sobre o Envelhecimento, cujas medidas têm três dimensóes prioritárias: idosos e desenvolvimento; promoção da saúde e bem-estar na velhice; e, ainda, criação de um ambiente propício e favorável ao idoso (ONU, 2003, p. 19).

Criado em $1^{\circ}$ de outubro de 2003, o Estatuto do Idoso foi sancionado pelo Presidente da República Luiz Inácio Lula da Silva, sob a Lei n. 10.741, com o objetivo de melhorar a qualidade de vida da pessoa idosa. Em resposta às estatísticas publicadas no quadro das pesquisas demográficas no país e no mundo, que constataram o crescimento alarmante do envelhecimento no planeta e as demandas de segmentos da sociedade civil e de organismos internacionais, como a ONU, o Brasil se viu obrigado a criar medidas imediatas para atender e garantir a saúde e a educação desses cidadáos.

$\mathrm{O}$ art. $3^{\circ}$ do Estatuto do Idoso determina a quem cabe a responsabilidade de cuidar da pessoa idosa, seguindo as orientaçóes do Plano de Ação Internacional sobre o Envelhecimento, da ONU:

Art. 3ํ É obrigação da família, da comunidade, da sociedade e do Poder Público assegurar ao idoso, com absoluta prioridade, a efetivação do direito à vida, à saúde, à alimentação, à educação, à cultura, ao esporte, ao lazer, ao trabalho, à cidadania, à liberdade, à dignidade, ao respeito e à convivência familiar e comunitária. (BRASIL, 2003) 
Entretanto, segundo Paula (2009, p. 37), no Capítulo V do Estatuto do Idoso há uma junção entre educação, lazer, cultura e esporte, como se todos fossem resumidos num único direito:

Essa dissolução do direito à educação em meio a outros direitos parece ter a finalidade de ocultar a reduzida efetividade no que se refere às conquistas no âmbito educacional, obtidas pelo Estatuto. [...] Notamos assim, que, no que se refere à educaçăo, o Estatuto do Idoso apresenta, essencialmente, medidas paliativas, uma vez que não trata, um só momento, do problema mais urgente que envolve a educaçấo na velhice: o analfabetismo de grande parte dos idosos. As leis apresentadas em concomitância com o Estatuto possuem caráter superficial, não significando nenhuma conquista efetiva para a maioria da população.

De acordo com Fernandes (2012), as pesquisas do IBGE constataram que $52 \%$ dos brasileiros considerados no grau de analfabetismo funcional estão entre os mais velhos, acima dos 50 anos. Diante do quadro, passou a ser imprescindível a luta pelo direito a uma educação acessível a todos.

Na implementação de políticas públicas no país, pelo menos em nível discursivo e ritualístico, continuou a preocupação com a situação do idoso. A Lei n. 11.433, de 28 de dezembro de 2006, criou o Dia Nacional do Idoso, a ser celebrado no dia $1^{\circ}$ de outubro de cada ano, ressaltando no parágrafo único do $1^{\circ}$ artigo que "os órgãos públicos responsáveis pela coordenação e implementação da Política Nacional do Idoso ficam incumbidos de promover a realizaçáo e divulgação de eventos que valorizem a pessoa do idoso na sociedade" (BRASIL, 2006).

A celebração de um dia para valorizar a pessoa idosa na sociedade, com efeito, pode ser considerada um avanço no nível das representaçóes e do campo simbólico. Contudo, seus efeitos na cultura e nas práticas sociais efetivas não são imediatos, por causa do habitus e da permanência das representaçóes preconceituosas que, muitas vezes, estigmatizam e desvalorizam os grupos minoritários.

Essas representaçóes estigmatizadoras podem ser algumas das causas da pouca visibilidade da pessoa idosa nas políticas públicas da EJA. Segundo Norbert Elias (2001, p. 80),

náo é fácil imaginar que nosso próprio corpo, táo cheio de frescor e muitas vezes de sensaçôes agradáveis, pode ficar vagaroso, cansado e desajeitado. Não podemos imaginá-lo e, no fundo, não o queremos. Dito de outra maneira, a identificação com os velhos e com os moribundos 
compreensivelmente coloca dificuldades especiais para as pessoas de outras faixas etárias. Consciente ou inconscientemente, elas resistem à ideia de seu próprio envelhecimento e morte tanto quanto possível.

Concomitante às transformaçóes biológicas, nessa terceira fase da vida acontece a aposentadoria, isto é, o desengajamento do mundo do trabalho e o descompromisso em relação a alguns papéis sociais da vida adulta (MASCARO, 2004, p. 41-42). Esse processo de desengajamento acontece não apenas no mundo do trabalho, mas também no interior de suas casas, nas quais os idosos são isolados.

Desse modo, frente a esse processo de desengajamento do mundo do trabalho, a matrícula de idosos na EJA muitas vezes é motivada por interesses pessoais, como aprender a ler e a escrever, elevar a autoestima. A esse respeito, Rouseane da S. Paula (2009, p. 38) afirma que

os idosos estão em franca desvantagem devido à falta do capital valorizado dentro do campo educacional, numa perspectiva capitalista: a juventude. $\mathrm{Na}$ visão que concebe a escola como espaço para qualificar mão de obra para o mercado, os idosos estáo a princípio, obviamente, descartados. Assim, contrariamente à educação permanente, encontramos a atuação reducionista da escola que limita sua ação social à qualificação para o mercado de trabalho, deixando de lado aspectos que incluem o desenvolvimento pessoal e social dos sujeitos, marginalizando os idosos não produtivos para o mercado.

A adaptação curricular deve ser contemplada na legislação mediante a reestruturação de propostas pedagógicas. Essa reestruturação é uma forma de flexibilizar o currículo na escola, onde o educador deve trabalhar uma educação inclusiva, que apresente a reformulação e a elaboração de estratégias de ensino e aprendizagem pautadas na formação integral do indivíduo. Os programas educacionais, sob esse ponto de vista, devem criar mecanismos que favoreçam o pleno desenvolvimento dos aspectos cognitivos, sociais, culturais e psicológicos inerentes aos seres humanos e à formação básica para a cidadania.

\section{Consideraçóes finais}

O elevado número de pessoas jovens, adultas e idosas analfabetas está relacionado à questão social que o próprio Estado impóe; dessa forma, antes 
de superar esse índice, primeiramente as políticas públicas implementadas deveriam atuar no combate as causas do problema.

O ensino no Brasil, a partir do Estatuto do Idoso, da Constituição e da LDBEN, conseguiu delinear mudanças para a Educação dos Jovens, Adultos e Idosos, de modo que desmistificou a caracterização de uma turma homogênea, ilustrada no preconceito de uma sociedade que, diante do envelhecimento, preferia ficar alheia à sua formação educacional.

No campo da educação, os idosos procuram a escola em busca de aprender a ler e a escrever, mas, acima de tudo, para combater o sentimento de incompetência diante da família e da sociedade. Em prol de sua satisfação pessoal, profissional e social, o idoso se insere na busca da independência.

De fato, o contexto social vivenciado nas salas de aulas e a concepção que a sociedade e a família têm sobre a terceira idade, de que são simplesmente seres dependentes, levam o campo educacional a repensar o ensino na EJA como uma ação transformadora, como enfatiza Silveira (2009, p. 21): "a educação transformadora contribui para o enfrentamento de desafios, como o das pessoas mais velhas, que se tornam resignadas, inferiorizadas e conformistas em face das agressōes de um mundo que rotiniza a vida”.

O processo de ensino, então, deve ser versado a partir do contexto sociocultural dos alunos, para que a aprendizagem possa nascer da realidade vivenciada por eles. Outrossim, abordar a temática do envelhecimento no ambiente escolar, como um dos fatores que impedem o exercício da cidadania, pode contribuir na busca dos direitos dos idosos e no respeito à diversidade, e fazer com que a autonomia seja alcançada por todas as faixas etárias de alunos da EJA.

Para o processo de ensino e aprendizagem na escolarização de jovens, adultos e idosos, é de suma importância a adaptação curricular, com o fim de atender os diferentes perfis que compóem esse grupo. Só a criação da LDBEN, com seus artigos específicos, do Estatuto do Idoso e a própria proposta curricular não são suficientes para a oferta de uma educação de qualidade.

Para Silveira (2009), garantir o cumprimento dos direitos e deveres das pessoas idosas na escola supóe a valorização do pleno exercício da cidadania como um dos princípios abordados na legislação, tanto do Estatuto do Idoso como da LDBEN. Constatou-se que os avanços no ensino da EJA estáo ligados aos investimentos em programas sociais, políticos e educacionais. 
Apesar das mudanças com a implantação do Estatuto e da Política Nacional do Idoso, da Constituição e da LDBEN, o Brasil ainda tem um longo caminho a percorrer para oferecer aos jovens, adultos e idosos um ensino de qualidade. $\mathrm{O}$ Estado precisa rever a sua atuação para traçar novas diretrizes para a EJA, em especial para a pessoa idosa, bem como para as demais fases ou modalidades de ensino. Em projetos políticos de cunho inclusivo, a aprendizagem vivenciada permite o nascimento da concepção de ser humano como um agente transformador da sua educação, capaz de traçar um novo caminho em sua vida, mediado pelos princípios de respeito, dignidade e liberdade ilustrados na legislação brasileira.

\section{Referências}

BRASIL. Constituição da República Federativa do Brasil. Brasília: Senado Federal, 1988. Atualizado em julho/2010.

BRASIL. Lei n. 8.842, de 4 de janeiro de 1994. Dispóe sobre a política nacional do idoso, cria o Conselho Nacional do Idoso e dá outras providências. Diário Oficial da União. Brasília: Imprensa Nacional, 5 jan. 1994, Seção I, p. 77.

BRASIL. Lei n. 9.394, de 20 de dezembro de 1996. Estabelece as diretrizes e bases da educação nacional. Diário Oficial da União. Brasília: Imprensa Nacional, 23 dez. 1996, Seção I, p. 27833.

BRASIL. Lei n. 10.172, de 9 de janeiro de 2001. Aprova o Plano Nacional de Educação e dá outras providências. Diário Oficial da Uniāo. Brasília: Imprensa Nacional, 10 jan. 2001, Seção I, p. 1.

BRASIL. Lei n. 10.741, de $1^{\circ}$ de outubro de 2003. Dispóe sobre o Estatuto do Idoso e dá outras providências. Diário Oficial da União. Brasília: Imprensa Nacional, 3 out. 2003, Seção I, p. 1.

BRASIL. Lei n. 11.433, de 28 de dezembro de 2006. Dispóe sobre o Dia Nacional do Idoso. Diário Oficial da Uniāo. Brasília: Imprensa Nacional, 29 dez. 2006, Col. 2, p. 28.

BRASIL. Decreto n. 6.093, de 24 de abril de 2007. Dispóe sobre a reorganização do Programa Brasil Alfabetizado, visando à universalização da alfabetização de jovens e adultos de quinze anos ou mais, e dá outras 
providências. Diário Oficial da União. Brasília: Imprensa Nacional, 24 abr. 2007, Seção I, p. 4.

CHAIMOWICZ, F. A saúde dos idosos brasileiros às vésperas do século XXI: problemas, projeções e alternativas. Saúde Pública, São Paulo: USP/ Faculdade de Saúde Pública, v. 31, n. 2, p. 184-200, abr. 1997.

DI PIERRO, M. C. A educação de jovens e adultos no Plano Nacional de Educação: avaliação, desafios e perspectivas. Educação \& Sociedade, Campinas, v. 31, n. 112, p. 939-959, jul./set. 2010.

ELIAS, N. A solidão dos moribundos. Seguido de Envelhecer e morrer. Tradução de Plínio Dentzien. Rio de Janeiro: Jorge Zahar, 2001.

FERNANDES, E. Dez anos depois, não saímos do lugar. Revista Nova Escola, São Paulo: Abril/Fundação Victor Civita, ano XXVII, n. 254, p. 92-95, ago. 2012.

FREIRE, P. Ação cultural para a liberdade e outros escritos. 12. ed. Rio de Janeiro: Paz e Terra, 2007.

GADOTTI, M.; ROMÃO, J. E. Educação de jovens e adultos: teoria, prática e proposta. 5. ed. São Paulo: Cortez/Instituto Paulo Freire, 2002. (Guia da Escola Cidadâ, v. 5).

HAIDT, R. C. C. Curso de Didática Geral. 7. ed. São Paulo: Ática, 2006.

INSTITUTO BRASILEIRO DE GEOGRAFIA E ESTATÍSTICA (IBGE). Estudos e Pesquisas, Informação Demográfica e Socioeconômica: Síntese de Indicadores Sociais, uma Análise das Condiçôes de Vida da População Brasileira, n. 27. Rio de Janeiro: Ministério do Planejamento, Orçamento e Gestão, 2010.

LOPES, A. O. et al. (Org.). Repensando a didática. 29. ed. Campinas: Papirus, 2011.

MASCARO, S. de A. O que é velhice. São Paulo: Brasiliense, 2004. (Coleção Primeiros Passos).

MOTTA, M. L. dos S. A terceira idade e seus direitos: a melhor idade contribuindo para o futuro. São Paulo: Léo Filho, 2005.

OLIVEIRA, R. de C. da S. Terceira idade: do repensar dos limites aos sonhos possíveis. São Paulo: Paulinas, 1999. 
ORGANIZAÇÃO DAS NAÇÓES UNIDAS. Plano de ação internacional sobre o envelhecimento. Tradução de Arlene Santos. Brasília: Secretaria Especial dos Direitos Humanos, 2003.

PAULA, R. da S. O não-lugar da pessoa idosa na educação. Práxis Educacional, Vitória da Conquista-BA, v. 5, n. 7, p. 29-43, jul./dez. 2009.

PLANO NACIONAL DE EDUCAÇÁO - proposta da sociedade brasileira. II Congresso Nacional de Educação (CONED). Belo Horizonte, 1997.

RUMMERT, S. M.; VENTURA, J. P. Políticas públicas para a educação de jovens e adultos no Brasil: a permanente (re)construçáo da subalternidade - consideraçóes sobre os Programas Brasil Alfabetizado e Fazendo Escola. Educar, Curitiba: UFPR, n. 29, p. 29-45, 2007.

SILVA, T. M. N. A construção de uma pedagogia para o idoso. Terceira Idade, São Paulo, v. 13, n. 25, p. 62-75, 2002.

SIlveirA, N. D. R.; BORTOlOZZO, M. C.; CARVAlHO, D. M. $A$ pessoa idosa: educação e cidadania. São Paulo: Secretaria Estadual de Assistência e Desenvolvimento Social; Fundação Anchieta, 2009.

UNESCO. Alfabetização de jovens e adultos no Brasil: lições de prática. Brasília: Unesco, 2008.

Recebido em: 13 ago. 2012

Aceito em: 12 set. 2012 